\title{
Analysis of the Corrosion Behavior of the TiNi Alloy in the Coarse-Grained State
}

\author{
Anna Churakova ${ }^{1,2, a^{*}}$, Elina Kayumova ${ }^{3, b}$, Evgeni Vorobievev,c and \\ Nafisul Haque ${ }^{4, d}$ \\ ${ }^{1}$ Institute of Molecule and Crystal Physics - Subdivision of the Ufa Federal Research Center of \\ the Russian Academy of Sciences, 151 pr. Oktyabrya, Ufa, 450075, Russia \\ 2Ufa State Aviation Technical University, 12 K. Marx str., Ufa, 450008, Russia \\ ${ }^{3}$ Ufa State Petroleum Technological University, 1 Kosmonavtov st., Ufa, 450064, Russia \\ ${ }^{4}$ Department of Metallurgical Engineering, NEDUET, University Road, Karachi 75270, Pakistan \\ achurakovaa_a@mail.ru, bkayumkaaaa@gmail.com, c'z.vorobyov@mail.ru \\ dengrnafis@gmail.com
}

Keywords: Shape Memory Alloys, Corrosive Behavior, Pitting Corrosion, Gravimetric Method, Passivating and Activating Solutions, Microstructure

\begin{abstract}
In this work was investigate the corrosion behavior of the TiNi alloy in a coarse-grained state in inorganic field with different concentration and holding time. An increase in the concentration of the solution leads to a significant acceleration of corrosion processes in the $\mathrm{Ti}_{49.1} \mathrm{Ni}_{50.9}$ alloy with a high $\mathrm{Ni}$ content, including until the samples are completely dissolved. It was revealed that solutions of $1 \mathrm{M}$ sulfuric and hydrochloric acids after a month's exposure did not change in color and no precipitations were found, while solutions of $5 \mathrm{M}$ hydrochloric and sulfuric acids acquired a violet and then green color, which is due to the predominant release of titanium ions $(+4)$ and nickel $(+2)$.
\end{abstract}

\section{Introduction}

In recent decades, materials with an ultrafine-grained structure have been created, having a grain size of $100-300 \mathrm{~nm}$, which have a unique structure and properties, they change fundamental characteristics, such as the Debye and Curie temperatures, saturation magnetization, etc. Shape memory materials (SME) have already found wide application in medicine as long-term functioning materials implanted into the body. A special class of shape memory alloys are nickel and titanium alloys - alloys (NiTi). The range of their application depends on the temperature of martensitic transformation and mechanical properties [1-6]. They exhibit high elastic properties, were able to change their shape when the temperature changes and do not collapse under conditions of alternating load. Phase transitions in such alloys are characterized by a wide hysteresis and a long temperature range, in which the material exhibits shape memory and superelasticity effects. It is known that various metal alloys have the ability to change their shape as a result of temperature changes. This effect is called "austenitic transformation", and another transformation, from austenitic state to martensitic state, is called "martensitic transformation" [7-8]. The biochemical compatibility of physiological fluids and metal implants is largely determined by the electrochemical interaction between them, which usually leads to the transfer of metal ions into tissue fluids. In this case, the implant may also contain heavy elements that are toxic to the body. However, it is impossible to assess biochemical compatibility by the concentration of toxic elements, especially if their introduction into the composition of the implant leads to a significant increase in its corrosion resistance [9-14]. Since the corrosive properties of the implant are the 
most important indicators of biochemical compatibility, it is necessary to take into account both the direct corrosion processes associated with the transition of ions through the interface, and the reactions leading to the formation of poorly conducting protective films. As a rule, such protective films delay the release of toxic ions into the tissue, as a result, the implant containing toxic elements weakly interacts with the surrounding tissues and becomes practically inert with respect to biological media [15-20].

Corrosion resistance is largely determined by the degree of defectiveness of the material and the peculiarities of its implantation into the human body as one of the most active carriers of aggressive media. Tissues are a complex biological system that reacts to the introduction of an implant by changing its own structure up to physical and mechanical destruction [21-23]. Therefore, it is important to know the features of corrosive behavior, affecting biochemical and biomechanical compatibility with body tissues.

\section{Material and methods}

The study material was a two-component alloy: $\mathrm{Ti}_{49.1} \mathrm{Ni}_{50.9}$ alloy, which has a $\mathrm{B} 2$ austenite structure at room temperature, with a bcc lattice of the $\mathrm{CsCl}$ type. To form a solid solution based on TiNi and to exclude the prehistory of obtaining the material, the alloy was quenched from the homogeneity region (from $800{ }^{\circ} \mathrm{C}$ ) into water. The average grain size of the hardened alloy was $200 \mu \mathrm{m}$. To reveal the microstructure of the initial titanium nickelide, an etchant of the following composition was used: $60 \% \mathrm{H}_{2} \mathrm{O}+35 \% \mathrm{HNO}_{3}+5 \% \mathrm{HF}$. The study of the microstructure was carried out on an optical metallographic microscope OLYMPUS GX51, as well as using scanning electron microscopy (SEM) JEOL JSM-6490LV, an inverted microscope AXIO OBSERVER Z1M in the dark field mode (the studies were carried out in the laboratory of solid state physics of the Institute of Physics of Molecules and Center of the Russian Academy of Sciences). Before testing, pre-prepared samples were weighed on an analytical balance, the samples were placed in a desiccator, where the test sample was in contact with an aggressive medium at a temperature (25 ${ }^{\circ} \mathrm{C}$ ). The samples were placed in the solution for a certain time until the appearance of noticeable traces of corrosion. After testing, the samples were washed with water, treated with alcohol, dried, and weighed on an analytical balance.

\section{Results}

Figure 1 shows optical microscopy of the surface of samples of the $\mathrm{Ti}_{49.1} \mathrm{Ni}_{50.9}$ alloy in a coarsegrained state.

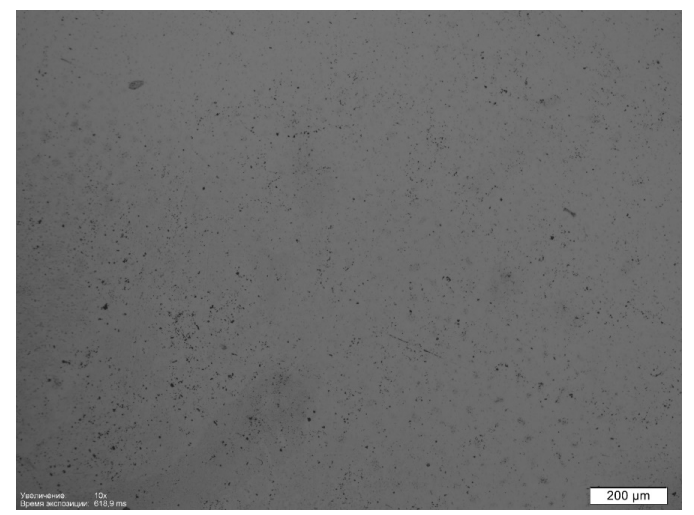

Fig. 1. Photographs of the surface of $\mathrm{Ti}_{49,1} \mathrm{Ni}_{50,9}$ alloy specimens before corrosion tests in coarse-grained state

Figure 2 shows the surface structures of alloy samples in a coarse-grained state after corrosion tests in a $1 \mathrm{M} \mathrm{H}_{2} \mathrm{SO}_{4}$ solution with different holding times. At a given concentration of the solution, 
no noticeable corrosion damage is observed; only corrosion products are observed on the surface of the samples. At the same time, with an increase in the exposure time in the solution, the amount and volume fraction of corrosion products increase linearly.

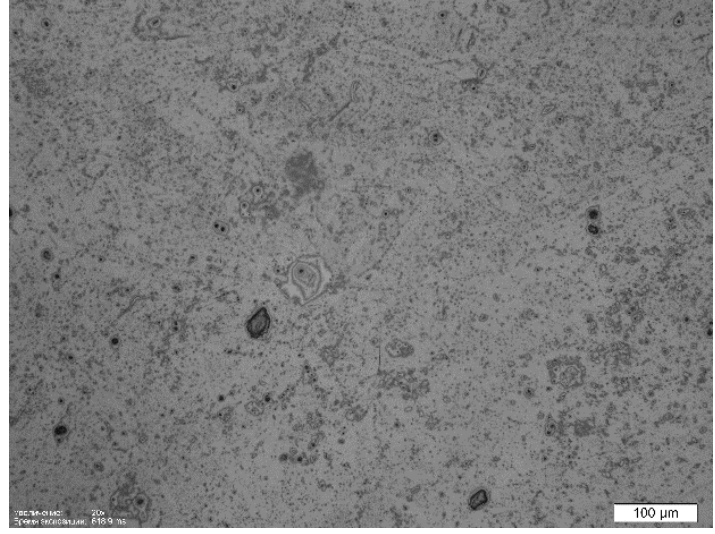

a)

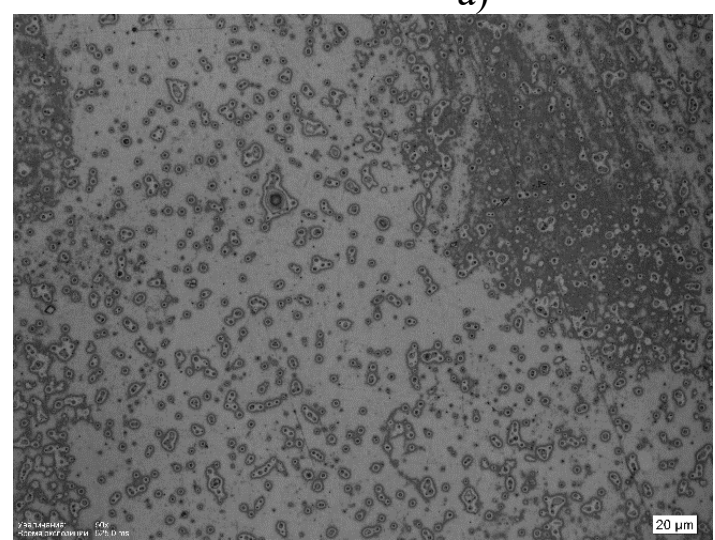

c)

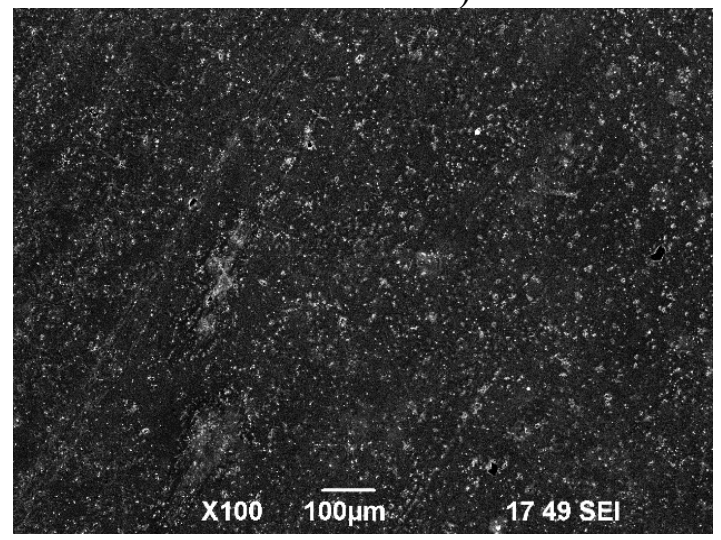

e)

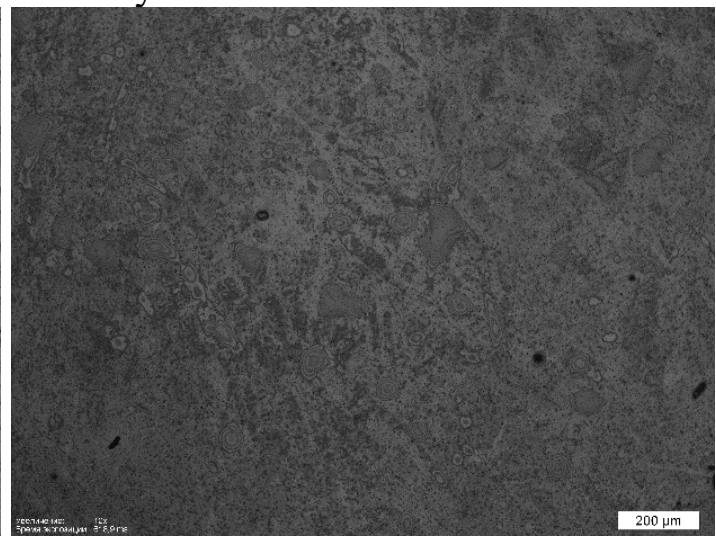

b)

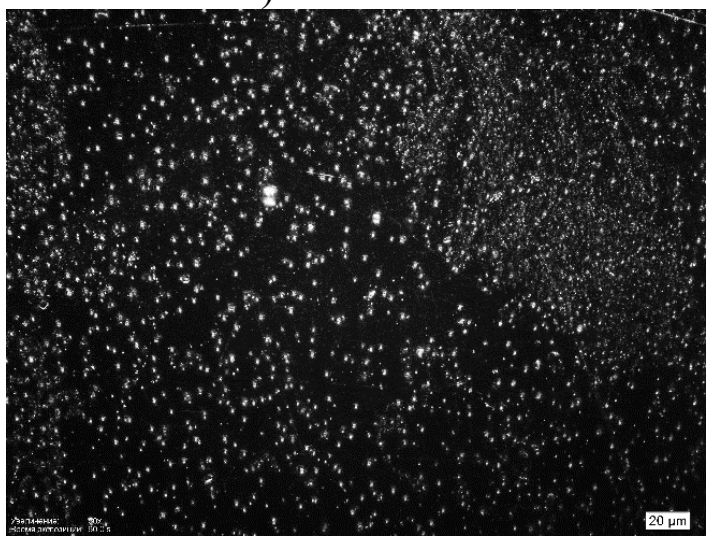

d)

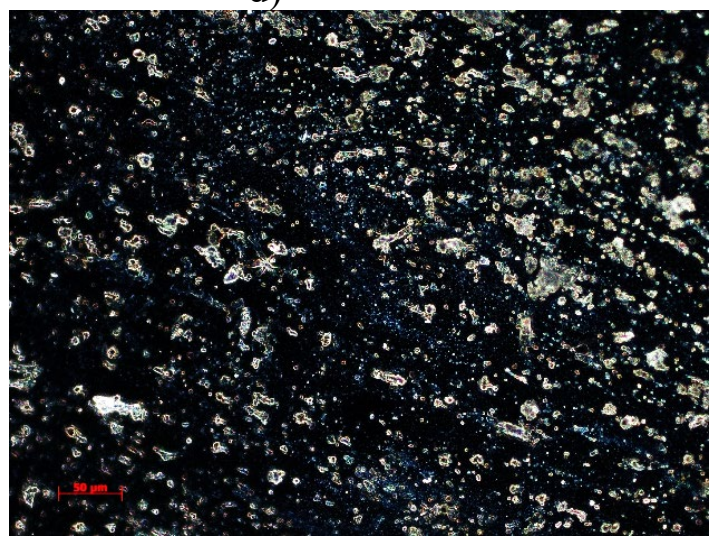

f)

Fig. 2. Photographs of the surface of Ti49.1 Ni50.9 alloy samples obtained using an optical microscope (a-d), SEM (e) and an inverted microscope (dark field) (f) in a solution of $1 \mathrm{M} \mathrm{H}_{2} \mathrm{SO}_{4}$ in a coarse-grained state: a) 1 day; b) 3 days; $c$-d) 15 days; $e-f) 30$ days

Corrosion tests in $1 \mathrm{M} \mathrm{HCl}$ also do not lead to damage to the samples, accompanied by an insignificant loss of sample weight, corrosion products are observed on the surface, the volume fraction is maximum at the maximum exposure time, small pitting is observed in some areas (Fig. $3, \mathrm{e})$. 


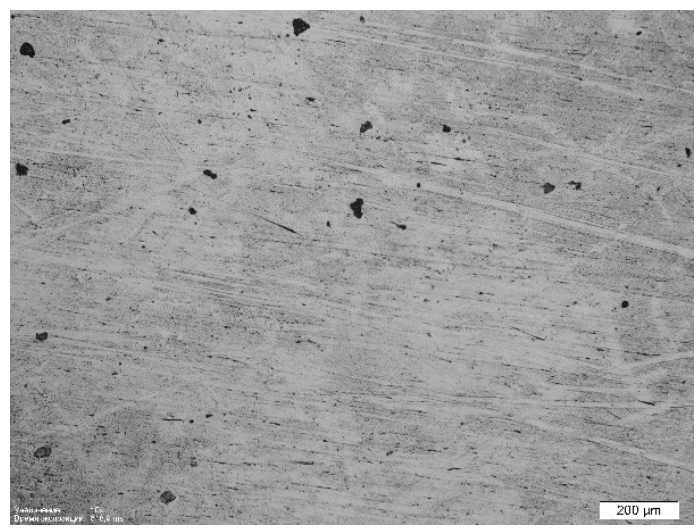

a)

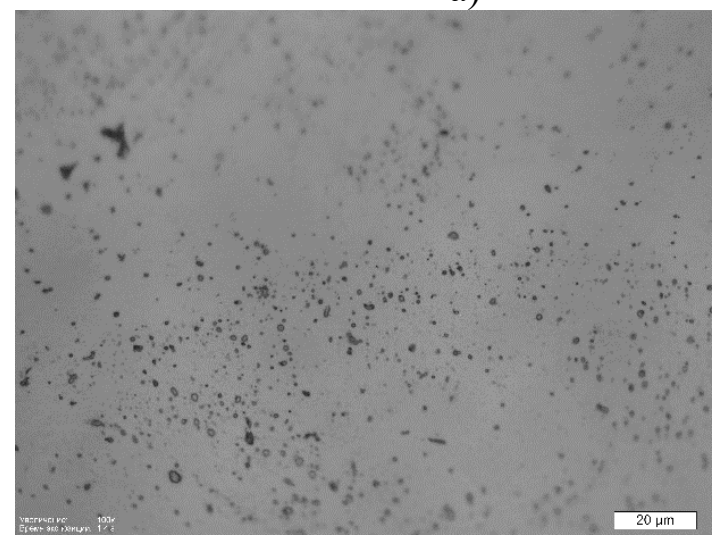

c)

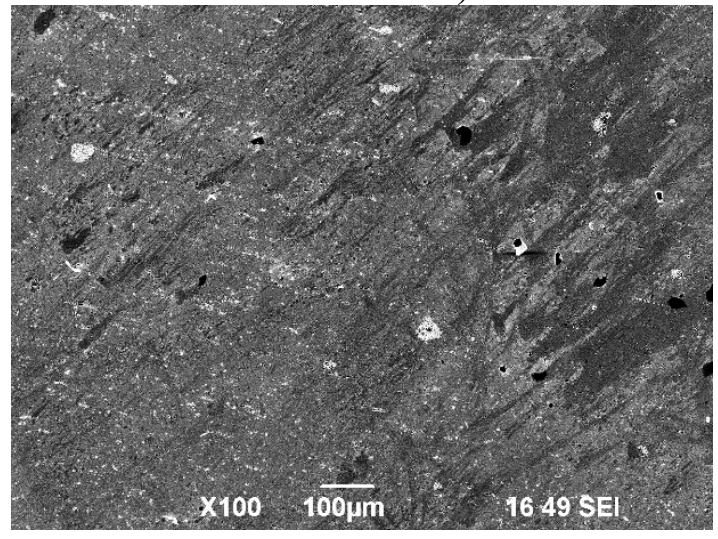

e)

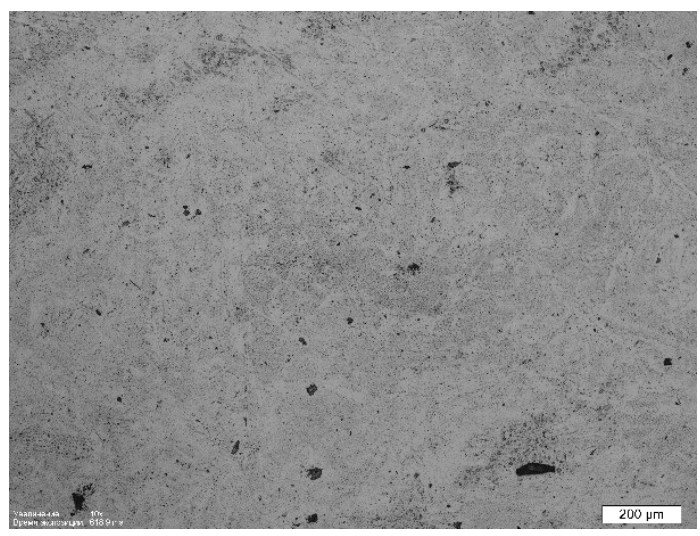

b)

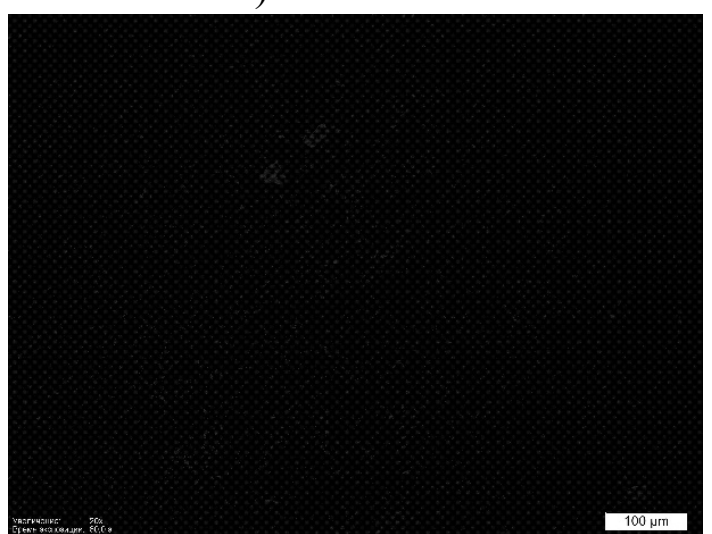

d)

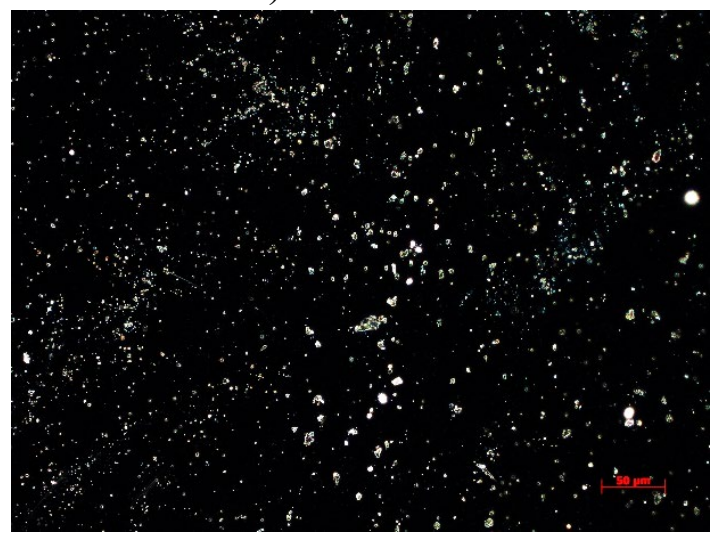

f)

Fig. 3. Photographs of the surface of Ti49.1Ni50.9 alloy samples obtained using an optical microscope (a-d), SEM (e) and an inverted microscope (dark field) (f) in a solution of $1 \mathrm{M} \mathrm{HCl}$ in a coarse-grained state: a) 1 day; b) 3 days; $c$-d) 15 days; e-f) 30 days

Studies in $3 \% \mathrm{NaCl}$ showed that, compared to tests in acid solutions, there is a smaller amount of corrosion products (Fig. 4). In this case, in the structure of the alloy, regions of different contrast with a size of about $400 \pm 30 \mu \mathrm{m}$ are distinguished at the maximum exposure time in the solution (Fig. 4, e). The maximum amount of corrosion products on the surface of the samples is observed after 15 days of exposure (Fig. 4, c-d). 


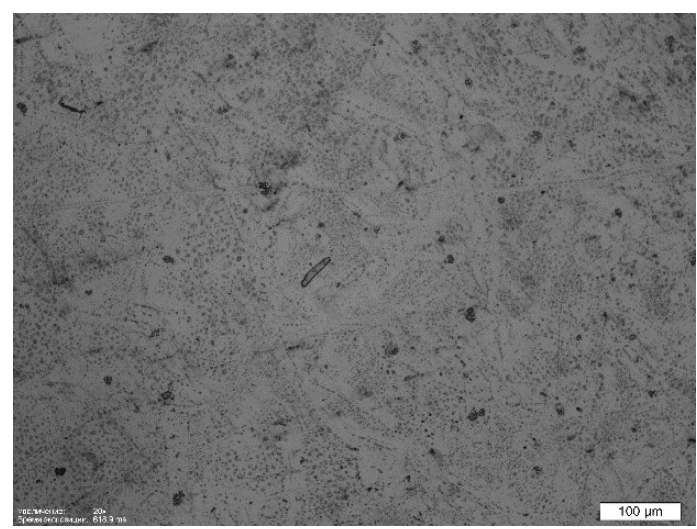

a)

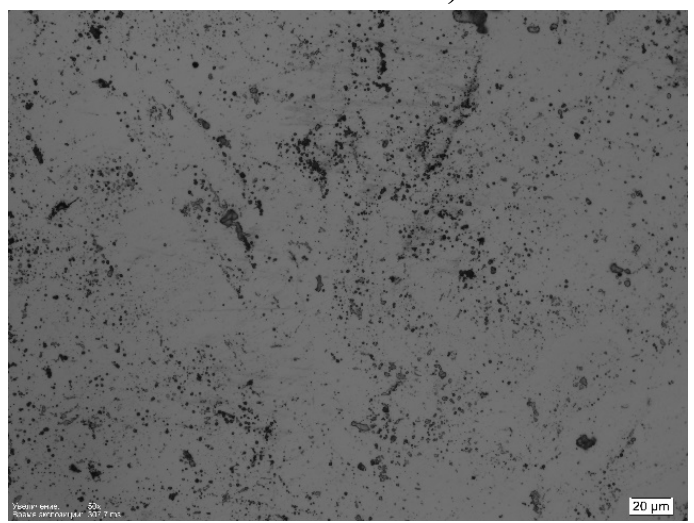

c)

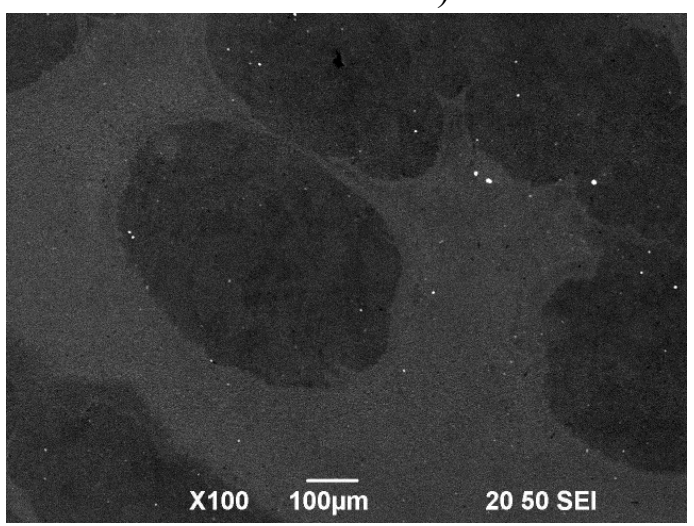

e)

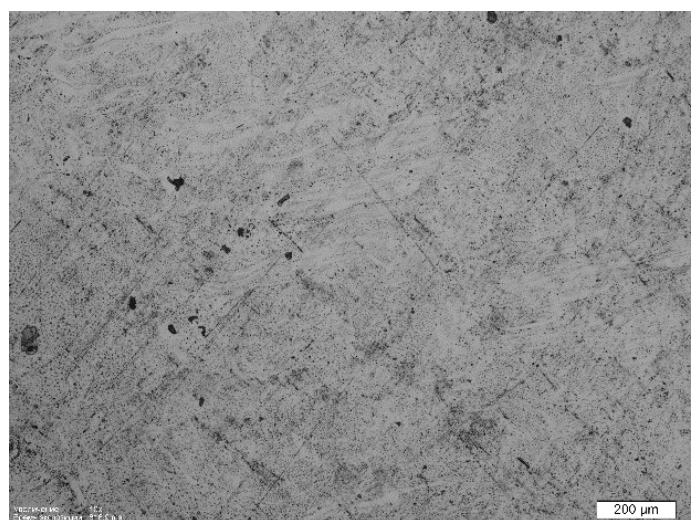

b)

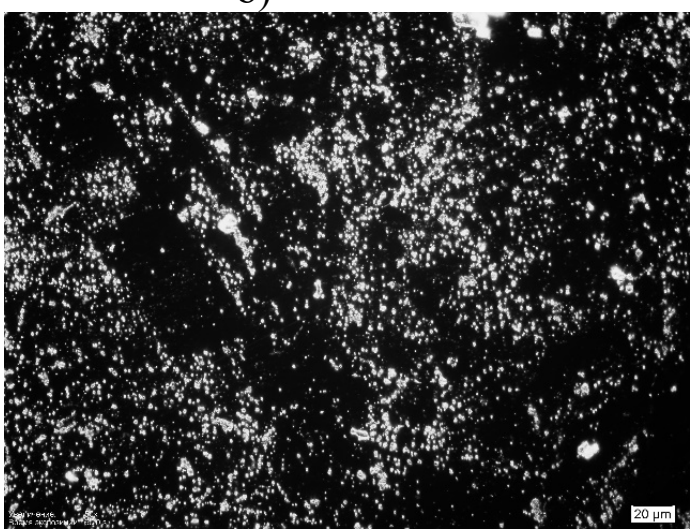

d)

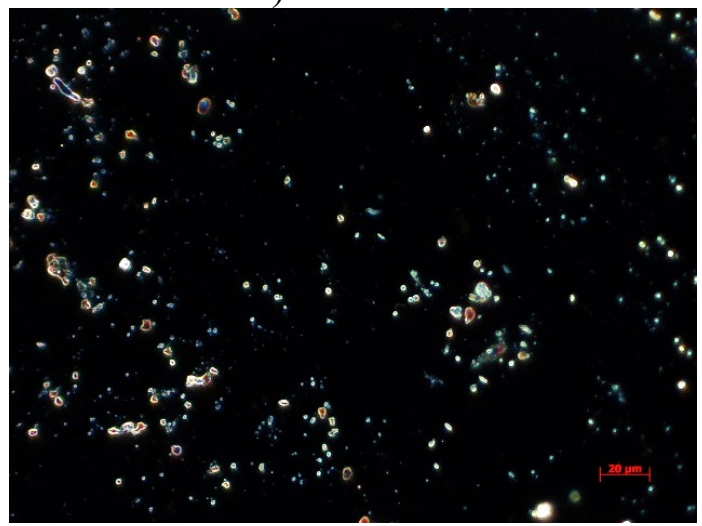

f)

Fig. 4. Photographs of the surface of $\mathrm{Ti}_{49.1} \mathrm{Ni}_{50.9}$ alloy samples obtained using an optical microscope (a-d), SEM (e) and an inverted microscope (dark field) (f) in a solution of 3\% $\mathrm{NaCl}$ in a coarse-grained state: a) 1 day; b) 3 days; $c$-d) 15 days; e-f) 30 days

Investigations of samples after corrosion tests in $5 \mathrm{M} \mathrm{HCl}$ on an inverted microscope (Fig. 5, $\mathrm{f}$ g) made it possible to determine the nature of corrosion damage. In the case of a coarse-grained state, deep pits are observed, occupying more than $50 \%$ of the sample surface. Studies using scanning electron microscopy also made it possible to estimate the average size and depth of pitting corrosion pits in the coarse-grained state (Fig. 5, e). The average size of the holes is about $100 \pm$ $10 \mu \mathrm{m}$. After 1 day of holding the samples in the solution, a large number of corrosion products are observed on the surface, significant damage with the formation of corrosion pits is observed on the 15 th day of exposure (Fig. 5, c-d). 


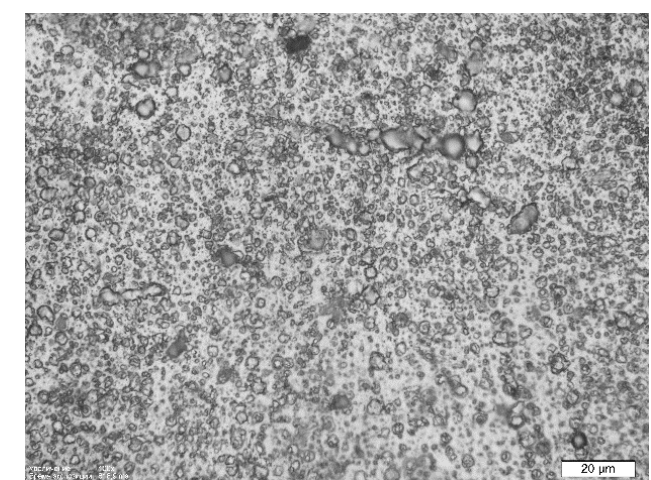

a)

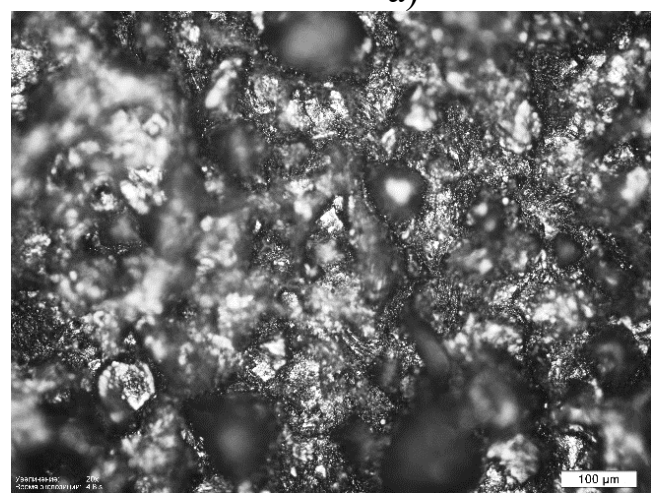

c)

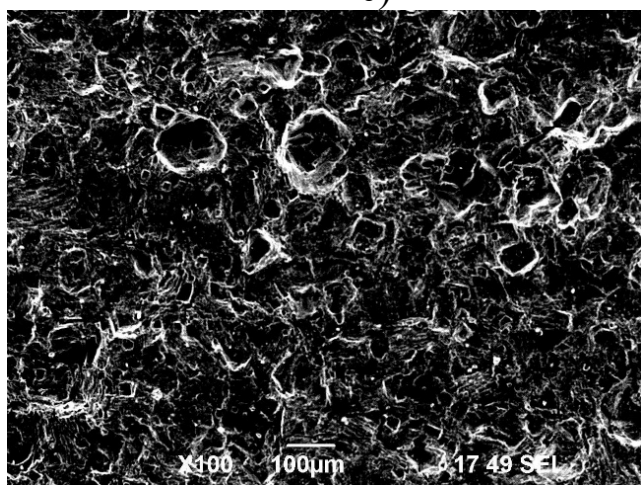

e)

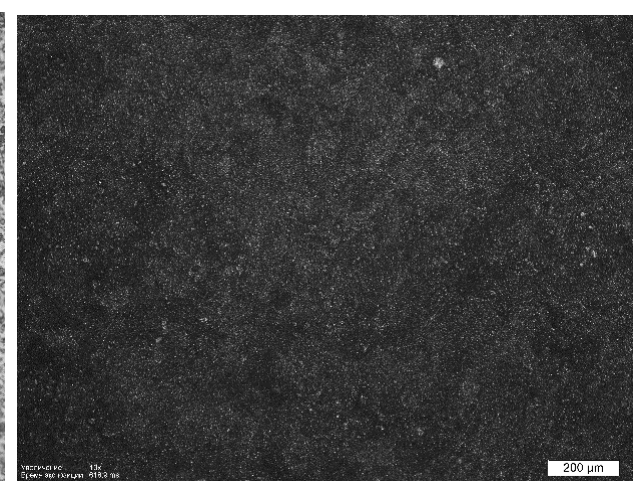

b)

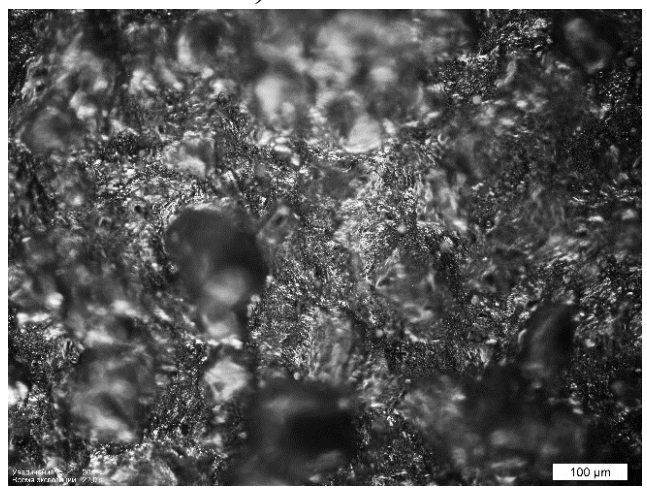

d)

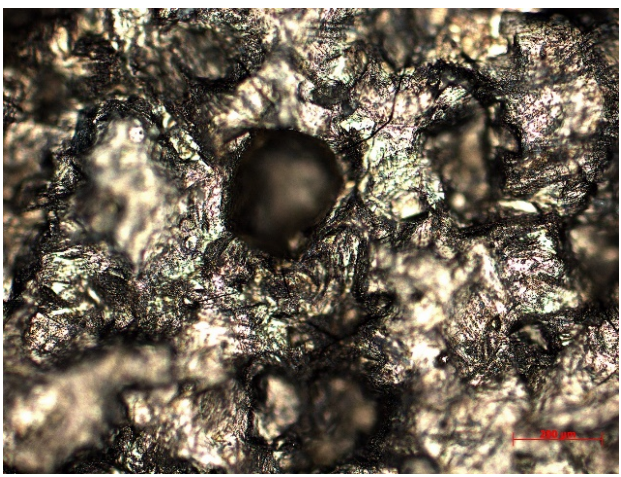

f)

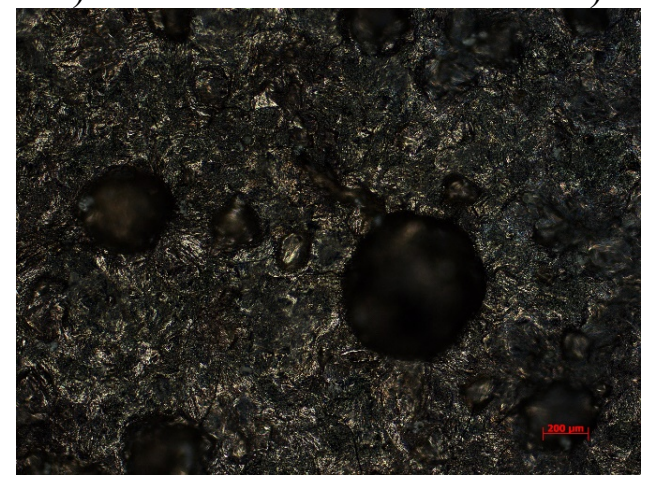

g)

Fig. 5. Photographs of the surface of Ti49.1Ni50.9 alloy samples obtained using an optical microscope (a-d), SEM (e) and an inverted microscope (dark field) (f-g) in a solution of $5 \mathrm{M} \mathrm{HCl}$ in a coarse-grained state: a) 1 day; b) 3 days; $c$-d) 15 days; e-g) 30 days 
Studies in solution showed that after 1 day, significant corrosion damage to the sample is observed (Fig. 6, a); after 3 days, the sample weight decreased by $50 \%$, followed by complete dissolution of the alloy sample in a $5 \mathrm{M} \mathrm{H}_{2} \mathrm{SO}_{4}$ solution.

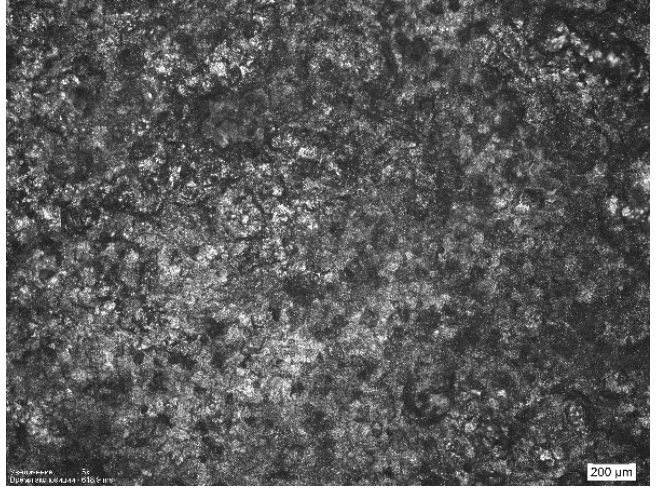

a)

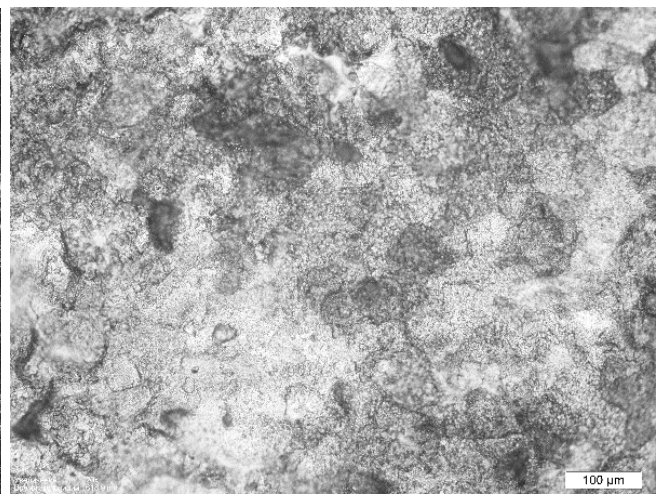

b)

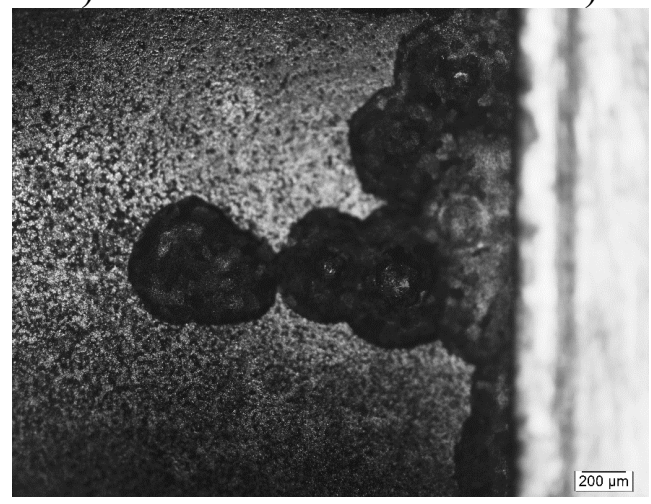

c)

Fig. 6. Photographs of the surface of Ti ${ }_{49.1} N_{50.9}$ alloy samples obtained using an optical microscope in a solution of $5 \mathrm{M} \mathrm{H}_{2} \mathrm{SO}_{4}$ in a coarse-grained state: $a$, b) 1 day; c) 3 days

\section{Conclusions}

An increase in the concentration of the solution leads to a significant acceleration of corrosion processes in the $\mathrm{Ti}_{49.1} \mathrm{Ni}_{50.9}$ alloy with a high $\mathrm{Ni}$ content, including until the samples are completely dissolved $\left(5 \mathrm{M} \mathrm{H}_{2} \mathrm{SO}_{4}\right.$ after 3 days of exposure; $5 \mathrm{M} \mathrm{HCl}$ is a significant proportion of corrosion damage after 30 days). It was revealed that solutions of $1 \mathrm{M}$ sulfuric and hydrochloric acids after a month's exposure did not change in color and no precipitations were found, while solutions of 5 $\mathrm{M}$ hydrochloric and sulfuric acids acquired a violet and then green color, which is due to the predominant release of titanium ions $(+4)$ and nickel $(+2)$. The process of dissolution of the $\mathrm{Ti}_{49.1} \mathrm{Ni}_{50.9}$ alloy in acid solutions at high concentrations follows the mechanism of pitting, which is confirmed by the photographs of the microstructures presented.

\section{Acknowledgment}

This work was supported by the Council for Grants of the President of the Russian Federation for State Support of Young Russian Scientists - Candidates of Science (MK-6202.2021.1.2).

\section{References}

[1] K. Otsuka, X. Ren, Prog. Mater. Sci. 50 511-678 (2005).

https://doi.org/10.1016/j.pmatsci.2004.10.001

[2] V. Brailovski, S. Prokoshkin, P. Terriault, F. Trochu, Shape Memory Alloys: Fundamental, Modeling and Applications (Ecole de Technologie Superieure, Quebec) 2003. 
[3] G.V. Kurdyumov, L.G. Khandros, Sov. Phys. Dokl. 66 211-214 (1949).

[4] J.W. Christian, The Theory of Transformations in Metals and Alloys (Elsevier Science, Oxford) 2002. https://doi.org/10.1016/B978-008044019-4/50022-2

[5] Z.L. Xie, B. Sundqvist, H. Hanninen, J. Pietikainen, Acta Metall. Mater. 41 2283-2290 (1993). https://doi.org/10.1016/0956-7151(93)90310-O

[6] V.V. Rubanik, V.V. Klubovich, V.V. Rubanik Jr., J. Phys. IV 112 249-251 (2003). https://doi.org/10.1051/jp4:2003876

[7] S.P. Belyaev, R.F. Konopleva, I.V. Nazarkin, A.I. Razov, V.L. Solovei, V.A. Chekanov, Phys. Solid State 49 1969-1972 (2007). https://doi.org/10.1134/S1063783407100265

[8] K. Inoue, K. Enami, Y. Yamaguchi, K. Ohoyama, Y. Morii, Y. Matsuoka, K. Inoue, J. Phys. Soc. Jpn. 69 3485-3488 (2000). https://doi.org/10.1143/JPSJ.69.3485

[9] Meisner L.L.,2006 Corrosion properties of TiNi-TiAu quasi-binary cut alloys in biochemical solutions Physics and chemistry of material processing $178-84$

[10] Ustinskaya T.N., 1987 Composition, electrochemical and protective properties of anode films on the TiNi intermetallide Electrochemistry 23 254-259

[11] Kossy G.G., 1978 Protection of metals 14(6) 662-666.

https://doi.org/10.1109/TAES.1978.308691

[12] Stepanova T.P.,1978 Protection of metals 14(2) 169-171

[13] Deryagina O.G., 1980 Electrochemical behavior of anodically oxidized Ni-Ti alloys in sulfate solutions containing chlorine ions Electrochemistry 16(12) 1828-1833

[14] Tan L., 2003 Corrosion and wear - corrosion behavior of NiTi modified by plasma source ion implantation Biomaterials 24 3931-3939. https://doi.org/10.1016/S0142-9612(03)00271-0

[15] Okazaki Y., 1998 Corrosion resistance, mechanical properties, corrosion fatigue strength and cytocompatibility of new Ti alloys without Aland V Biomaterials 19 1197-1215.

https://doi.org/10.1016/S0142-9612(97)00235-4

[16] Hofman A., 1996 Classes of materials used in medicine Biomaterials Science Academic Press 37-50. https://doi.org/10.1016/B978-0-08-050014-0.50007-9

[17] Shabalovskaya S.A., 2002 Surface, corrosion and biocompatibility aspects of nitinol as an implant material Bio-Medical materials and Engineering 12 69-109

[18] Liu Chenglong, 2006 In vitro electrochemical corrosion behaviour of functionally graded diamound-like carbon coatings on biomedical Nitinol alloy Thin Solid Films 496 457-462.

https://doi.org/10.1016/j.tsf.2005.09.109

[19] Shevchenko N., 2004 Studies of surface modified NiTi alloy Applied Surface Science 235 126-131. https://doi.org/10.1016/j.apsusc.2004.05.273

[20] Vandenkerckhove R., 2004 Corrosion behaviour of a superelastic Ni-Ti alloys Materials Science and Engineering 378 532-536. https://doi.org/10.1016/j.msea.2003.11.072

[21] Denton M., 2005 Corrosion evaluation of wear tested nitinol wire Materials Science and Engineering 25 276-281. https://doi.org/10.1016/j.msec.2004.12.009

[22] Xiao Xu, 2004 Shock synthesis and characterization of nanostructured NITINOL alloy Materials Science and Engineering A 384 194-201. https://doi.org/10.1016/S09215093(04)00812-3

[23] Primak O., 2005 Morphological characterization and vitro biocompatibility of a porous nickel-titanium alloy Biomaterials 26 5801-580.

https://doi.org/10.1016/j.biomaterials.2005.02.029 